\title{
Benefits of systems thinking for a human and organizational factors approach to safety management
}

\author{
Jean-François Vautier ${ }^{1,2,3}$ (I) - Nicolas Dechy ${ }^{4} \cdot$ Thierry Coye de Brunélis $^{5} \cdot$ Guillaume Hernandez $^{1} \cdot$ Richard Launay $^{1}$. \\ Diana Paola Moreno Alarcon ${ }^{6}$
}

Published online: 4 June 2018

○) Springer Science+Business Media, LLC, part of Springer Nature 2018

\begin{abstract}
This paper highlights the value of systems theory and its application to human and organizational factors (HOF). HOF specialists consider multiple systems characteristics in their analyses but are often unaware of the relevant theory applied in their analysis. We argue that a structured effort to take key systems characteristics into account in HOF practice would increase the depth and breadth of safety management analyses and help HOF specialists to act more effectively on industrial socio-technical systems. First, the paper identifies the following seven system theory characteristics: constitution, multi-axis representation, limit, emergence, variety, coherence, and causal interaction, which are then illustrated with examples from the HOF field. Finally, we discuss the two main benefits of integrating system thinking in a HOF approach to safety management: (1) an improved understanding of the inner workings of an industrial socio-technical system; and (2) a compendium or a reference to guide for decision-making and the implementation of actions within the industrial socio-technical systems.
\end{abstract}

Keywords Human and organizational factors $\cdot$ Systemic approach $\cdot$ Safety $\cdot$ Systems thinking $\cdot$ Emergence $\cdot$ Variety $\cdot$ Coherence $\cdot$ Causal interaction

\section{Introduction}

Jean-François Vautier

jean-francois.vautier@cea.fr

Nicolas Dechy

nicolas.dechy@irsn.fr

Thierry Coye de Brunélis

thierry.coyedebrunelis@thalesgroup.com

Guillaume Hernandez

guillaume.hernandez@cea.fr

Richard Launay

richard.launay@cea.fr

Diana Paola Moreno Alarcon

diana.moreno@mines-paristech.fr

1 CEA (French Atomic Energy and Alternative Energies Commission), Gif-sur-Yvette, France

2 INSTN (National Institute for Nuclear Science and Technology), Gif-sur-Yvette, France

3 AFSCET (French Society of Systems Science), Paris, France

4 IRSN (Institute for Radiological Protection and Nuclear Safety), Fontenay-aux-Roses, France

5 THALES, Cholet, France

6 MINES ParisTech/PSL Research University, Paris, France

\subsection{Goals and definitions}

This article reduces the gap between research conducted in systems thinking and the practical application of this research within organizations. This is accomplished by applying results from systems theory to the human and organizational factors (HOF) approach to safety management. First, this paper describes and reviews seven system characteristics currently used in a HOF approach to the study of industrial socio-technical systems that include work situations, design projects, and high-risk organizations. Then, the paper details the two main benefits of using these system characteristics in a HOF approach to safety management.

Several definitions are evoked in order to address the scope of this article. HOF is devoted to the study of industrial socio-technical systems, ranging from workplaces to entire industrial plants (Tosello and et Vautier 2001). An industrial socio-technical system consists of elements of various sizes that combined to achieve specific goals (Manna 2007; IAEA 2013). These elements include workers or technical devices such as tools, or machines. Given that multiple 
basic elements are organized to perform one or several tasks according to procedures and safety rules, a workshop in an industrial plant can be regarded as a set of basic elements.

The seven systems' characteristics we consider originate from general systems theory described by Von Bertalanffy (1968). Von Bertalanffy proposed an integrative or systemic approach to the study of systems. When a systemic approach is contrasted with a reductionist approach (Descartes 1637), it appears that the latter seeks to understand systems through the analysis of their element, while the systemic approach is more inclusive. General systems theory takes into consideration other systems' characteristics, such as the arrangement and the interaction between the elements, as a sizable quantity of the performance of the system can be attributed to these other characteristics (Le Moigne 1977).

Human and organizational factors (HOF) utilize a systemic approach that is focused around the object of study. Specifically, they focus on industrial socio-technical systems through the use of system characteristics. From a human and social science perspective, HOF are dedicated to studying workers' performance as well as the factors that directly or indirectly influence this performance (Tosello and et Vautier 2001; Manna 2007; IAEA 2013). Certain factors pertain to the local work situations (Reason et al. 2006) and hence directly influence human performance; these include the operators' skills, their tasks, as well as the tools at their disposal. In contrast, other factors pertain to the larger sociotechnical systems (Rasmussen 1997; Leveson 2004) and interact with the local work situation, thus influence human performance indirectly. These organizational factors include the design aspects of work situations; the upkeep of these work situations; the methods used to share information such as company incidents, operator feedback, audit loops; and the regulator's level of control.

More specifically, the HOF approach to safety management is concerned with human failure and the unsafe acts carried out by workers, as well as the factors within the system that influence human performance directly or indirectly; viewed from a human and social science perspective. In 2012, France formally defined HOF, in a decree pertaining to nuclear sites ${ }^{1}$ as "the factors that influence human performance, such as skills, work environment, task characteristics, and organization." Numerous academic authors (Dekker 2006, 2011; Hollnagel et al. 2006, 2012; Leveson 2004; Perrow 1984; Rasmussen 1997; Rasmussen and Svedung 2000; Reason 1997) make claims both advertently and inadvertently, as to the value of system approaches in their publications of HOF accident models and related HOF methods. Certain scholars (Grant et al. 2018) even identified common

\footnotetext{
${ }^{1}$ In the "Arrêté du 7 février 2012 fixant les règles générales relatives aux installations nucléaires de base".
}

"system thinking tenets" across the multiple popular models developed by other academic authors. In their analysis, they identified of 15 common systemic concepts or tenets that influence accident models from a diversity of authors. Our focus is different; in that this study focuses not only on the analysis of accidents or unwanted events, but it also focuses on assessing the day-to-day normal activities, which constitute a significant aspect of the HOF studies. Furthermore, this study examines the benefits of several system characteristics from the perspective of a HOF practitioner.

Consequently, several tenets previously identified by scholars are more detailed than the system characteristics proposed in this paper. Specifically, tenets such linear and non-linear interactions, feedback loops, and the sensitive dependence on the initial condition are further categorized, in comparison to the notion of causal interaction in our paper which regroups a number of these terms. Nonetheless, none of the tenets previously identified examine the concept of coherence, a notion strongly linked to HOF practice.

Moreover, few implicit or explicit references of systemic approaches in professional HOF guidelines to safety management were found. For example, a survey carried out by ESReDA on the practices employed during accident investigation, analyzed the replies from 49 European respondents and identified a low use of systemic models in the early 2000s (Dechy et al. 2012). Finally, other scholars such as Underwood and Paterson (2013) have highlighted and addressed the gap that remains between safety management theory and its practical implementation; one notion of this gap includes systemic accident analysis.

\subsection{Approach}

Our final goal is to contribute to the safety management field by transferring theoretical results from the field of systems research to the practice of HOF to safety management. As HOF practitioners in high-risk industries, and in accordance with the IAEA (2016) recommendation, we recognize a need to develop a guide of approaches, methods, and tools that will facilitate the implementation of systemic practices in the HOF approach to safety management. This is why the focus of this paper is on the benefits of systems thinking for HOF. Our qualitative feedback indicates that HOF specialists often consider several system characteristics but in an implicitly manner. In fact, the benefits of a systems approach are not evident to many HOF specialists. Consequently, this review may enable HOF specialists to more easily relate to systems thinking and thus consider additional system characteristics during their analysis. This paper presents a qualitative research drawing of the authors' personal experience as HOF specialists working in high-risk industries (e.g., nuclear and chemical industries). With the exception of the last co-author who is a Ph.D. student, the first five co-authors 
each have between 10 and 25 years of experience as risk analysts in high-risk industries, and the same number of years as HOF specialists. Three authors hold HOF degrees specializing in ergonomics at both a Masters and Ph.D. level, and two authors graduated as engineers. They are involved in a network of expert work groups surrounding topics such as nuclear safety management and HOF (OECD \& IAEA); risk management from a cross-industry perspective; French HOF groups in non-profit associations (IMdR, ICSI); and systemic science societies or associations in France (AFSCET) and at the European level (ESReDA).

In a few words, we built a focus group of a variety of experts to tackle questions using elicitation techniques to determine the benefits of system characteristics. We worked independently and then come together during several working meetings, to generate a non-exhaustive list of system characteristics. From this list, we identified seven key system characteristics currently used in the HOF approach to safety management and discussed the benefits of systems thinking for HOF.

Unanimous consensus from all of the co-authors was used as the control in this qualitative study. The seven characteristics of a system are presented and include constitution, multi-axis representation, limit, emergence, variety, coherence between factors, and causal interaction. For each of these characteristics, one or more HOF illustrations will be presented. Next, we elaborate on the two main benefits of using systems characteristics in HOF: firstly to improve our understanding of how an industrial socio-technical system functions; and secondly to guide actions carried-out within industrial socio-technical systems. Thus, we illustrate several ways to address the recent recommendations from the International atomic energy agency (IAEA) regarding the implementation of systemic approaches; approaches that they define as relating to the system as a whole in which the interactions between technical, human, and organizational factors are duly considered (IAEA 2016).

\section{Seven system characteristics used in a HOF approach to safety management}

\subsection{Constitution of a system}

There are many definitions of a system that exist [cf. Von Bertalanffy (1968) or Le Moigne (1977)]. However in this paper, we consider only two of these definitions: the first from De Rosnay (1975), which is representative of the current definitions of a system, and the second from Aristotle, chosen for its originality as the concept of "creating the system' is included within the definition itself.

De Rosnay (1975) defines a system as a set of elements that interact together in a dynamic way, a set that is organized to achieve a goal. The second definition is derived from the notion of causes in Aristotle's "Physics" and "Metaphysics" (cf. the translations of these two books in 1930, 2008 in references) and groups a system into four aspects. Indeed, when considering any kind of system, we can identify four aspects of this system that relate to Aristotle's four causes (Vautier 2008, 2015). Therefore, a system is:

- Connected to the material cause: the elements of the system;

- Connected to the formal cause: the structure of the set of elements of a system and hence the arrangement of these elements;

- Connected to the final cause: this is the reason why this set of elements, assembled as a system, exists. Indeed, a system exists to achieve one or several goals and hence to do (and often also to make) something;

- Connected to the moving cause: the process of designing, making and maintaining the system.

In a HOF approach to safety management, the systems studied are industrial socio-technical systems, and hence all of the aspects indicated above are considered in a HOF approach. Furthermore, the concept of "a factor" is an additional notion that is used in this discipline. In fact, this "factor" is a general concept used to evoke all sources that influence the human performance in an industrial socio-technical system; this may be an element, a structure, a goal or a process (cf. Aristotle's definition above).

In practice, two types of systems may be considered in a HOF approach (Reason et al. 2006). The first type of system is a local work system that is often called the "work situation." Here, workers and machines or tools are elements that interact with one another in a work environment to achieve performance goals (goals of production, of quality, and of delays), while at the same time meeting safety requirements. Some examples of work situations include a driver using the pedals and the steering wheel to drive the car, or a pilot within an aircraft cockpit. The second type of system interacts with the first local systems and conditions their quality. This may be a factory department (operation, maintenance, Health, Safety and Environment) or the project teams dedicated to designing and maintaining the work situations. This second type of system can also include the facility itself or external systems such as groups of companies, subcontractors, or regulators. The external systems such as groups of companies are dedicated to improving company safety, via an exchange of data about incidents that will ultimately induce changes in the work situations (first type of system). Most aspects of these systems (second type) are governed by processes (engineering, maintenance) and are therefore constraint to several local work situations. 
In other words, the local work system referred to as "the work situation" may be defined according to the first three causes proposed by Aristotle, while the second kind of systems may be described by to the moving cause.

\subsection{Multi-axis representation of a system}

A very important step in systems thinking, and hence in its practical implementation, involves the analyst producing an accurate description of the complex system prior to acting on it. This systemic approach provides modeling tools such as the tool of "systemic triangulation" (Le Moigne 1977), the later which suggest the analyst considers three ways or aspects to represent a system:

- The functional aspect (what the system does, its aim, how it is used, its behavior and the impact on the environment),

- The structural aspect (what the system is from an ontological point of view, focusing on the structure from an analytical dimension but with an emphasis on the relationships rather than the elements),

- The historical aspect (what the system becomes, from a genetic or dynamic point of view, its past and future or project, including its memory and self-organization).

In other words, the systemic triangulation approach is based on the triad of the doing, the being and the becoming. One should consider that these three ways to model a complex system should be combined iteratively to yield a deeper and deeper understanding.

In a HOF approach to safety management, the functional aspect of the systemic triangulation was introduced through the notion of system failure (Bignell and Fortune 1984; Perrow 1984) and system functions (e.g., Rasmussen 1997; Ramussen and; Svedung 2000; Leveson 2004; Hollnagel 2012). The structural aspect, the engineering approach, and the concept of relying on the analytical paradigm (e.g., Descartes 1637) are persistent even today in the mindset of many high-risk system actors.

We observed that safety analysts and architects increasingly acknowledge the systemic approach, particularly as it is the human and social science researchers and analysts that have been involved in the safety assessments. However, this acknowledgement comes only after several major accidents in high-risk systems (Wilpert and Fahlbruch 1998), which led analysts to consider three arguments: (1) the role that humans and the organization played in these accidents (e.g., collision of two airplanes at takeoff in Tenerife in 1977, nuclear power plant meltdown in Three Mile Island in 1979); (2) the importance of the interactions between the different levels of the socio-technical system (Rasmussen 1997) (e.g., the explosions of the chemical plant at Bhopal in 1984, of the space shuttle Challenger in 1986 and of the Chernobyl nuclear power plant in 1986); and (3) the interorganizational aspect of the accident (e.g., the Paddington collision in 1999, the Columbia space shuttle loss in 2003).

Finally, in ergonomics, the historical aspect of the system is emphasized as the "diachronic" aspect of a system (Vautier et al. 2016). Several safety researchers, from the human and social sciences field, have established concepts such as the incubation period to denote the historical dimension of the accident (Turner 1978). These are moments during which weak signals of a threat to safety were not recognized in time to prevent a major accident. There are latent errors (Reason 1990), which unlike active errors do not immediately cause an accident but are later combined or synchronized with another accidental sequences. Among them, there are pathogenic organizational factors (Reason 1997; Dien et al. 2004; Dien 2006), which are the recurring root causes of accidents that negatively influence safety for years before an accident occurs.

This historical dimension is increasingly recognized and often combined with a sociological perspective (socio-historical approach), as is the case in Vaughan's (1996) analysis of the Challenger space shuttle accident. An organizational analysis approach (Dien et al. 2004, 2012; Rousseau and et Largier 2008; Llory and et Montmayeul 2010; Dechy et al. 2011; Dien 2006) has been developed as a tool to investigate accidents and to diagnose and assess safety management. It combines the structural aspects of the system (socio-technical, multi-level, inter-organizational) with the temporal aspect of the system's history and dynamics, while also taking into account possible safety degradations and improvements.

\subsection{Limit of a system}

In systems thinking, the limit of a system is the boundary that defines that which is inside and outside of the system. This limit is dependent on the actor or analyst's point of view.

In a HOF approach to safety management, the system studied may be the "system of causes" during an unwanted event analysis. For example, in the case of a leaking pipe, we may consider the following question "What does this unwanted event depend on?" While an engineer may focus on technical aspects such as the technical barriers (the wall thickness of the pipe, the kind of materials used), a HOF specialist may enlarge the system and focus on the role of humans and the organization in the maintenance of these barriers. Finally, an economist may continue to further enlarge the system by considering not only on the costs of the technical and human elements, but also on the budget assigned to the facility. 
The usage of system of causes in unwanted event analyses to cover organizational and social explanations has been continuously growing over the past several decades. For example, the partial core meltdown of one of the reactors of Three Mile Island (TMI) in 1979 appears to be the triggering point of a trend towards an investigation of human and later organizational factors. Indeed, initial analysis of this accident identified weaknesses in the design process of the control board's man-machine interface, a design fault that induced an incorrect operating view of the process. Afterwards, further analysis has shown that the company operating the TMI nuclear power plant had not examined feedback from other companies detailing similar issues with the man-machine interface on the control board. These problems were known by other companies in the US and Europe.

It would seem that Ernst Haeckel's (1899) famous quote regarding the theory of recapitulation is pertinent in unwanted event analysis. Ernst Haeckel's phrase "ontogeny recapitulates phylogeny" infers that the stages of development of the embryo of an animal, from fertilization to gestation (ontogeny), resemble the different stages of evolution of that animal's ancestors and hence of the species (phylogeny). However, this theory is merely a simple metaphor given that this theory has been largely discredited in biology.

It can thus be noted that all causal analyses begin with a technical or human failure. Next, the local factors of the work situation are considered. After that, the focus turns to other factors that influence the systems and that interacted with the local factors. However, from a historical point of view, we observe that links between human failure and their underlying HOF causes were not evoked in the past. In fact, in many of these past analyses human error was always related to lack of attention from the worker. But more and more, the limit of the system of causes is increasingly being considered.

\subsection{Emergence of a system}

The concept of emergence was introduced by Mill (1862) and Lewes (1875). It implies that the properties of a system result only in part from the properties of its elements. Lewes illustrated this concept by indicating that the properties of water are different from the properties of its components, hydrogen and oxygen. Similar ideas can be found in many disciplines. Several centuries BC, Aristotle indicated that the system contains properties, which are non-existing in its parts. Several decades later, Koffka (1935), a Gestalt psychologist stated, "the whole is other than the sum of its parts." One current example of these statements includes a plane's ability to fly while its individual parts cannot fly. These considerations are in fact other ways to express the concept of emergence.
In practice, emergence can be defined as the performance of a system, a performance that can incur changes if the arrangement of its elements also changed (Vautier 2007). In general, several emergences may occur within the same system.

Elements can be further classified by their spatial arrangement, temporal arrangement, or functional arrangement.

\subsubsection{Spatial arrangement}

The spatial arrangement may concern the different shapes of the same molecule (set of interconnected atoms). For example, isomers are molecules, which consist of the same elements (here atoms) but are arranged differently from each other. They may be stereoisomers in which one isomer is the mirror image of the other.

In a HOF approach to safety management, we can illustrate spatial arrangement by comparing the organization of two training rooms a $U$ shape row of tables that maximizes student communication, while several straight rows of tables positioned one behind the other tend to curtail it.

\subsubsection{Temporal arrangement}

The temporal arrangement concerns two types of arrangements: the absolute and the relative. As an illustration, let us consider elements like the sequential lectures of a meeting. From an absolute point of view and when looking at the timing, it is important to consider the kinds of lectures that will be held prior and after lunch. Both lectures will be difficult to follow, even if their reasons differ as in the first case people tend to feel hungry and in the second case they tend to feel sleepy. From a relative point of view, the lecture that follows a brilliant speaker will be less appreciated than if the lecture had followed a speaker of a similar level. Similarly, during a training session with two similar successive presentations, students may feel that the repetition is meaningless.

In a HOF approach to safety management, we can identify another example of ineffective temporal arrangements in the 1979 nuclear accident of TMI (Llory 1999). It deals with an inadequate spatial and temporal arrangement of the alarms displayed in the control board. During the accident, numerous alarms beeped and lit up simultaneously all over the control board, making it impossible for the workers to react to them. Since then, the literature has introduced hierarchies of alarms to prevent this kind of problem from reoccurring [cf. the notion of alarm management (Hollifield and Habibi 2010)].

\subsubsection{Functional arrangement}

Finally, the last kind of arrangement is the functional arrangement. It concerns the functional complementarity 
of the elements and their ability to be efficient together. It is why, during a meeting, for example, it may be interesting to combine theoretical and practical lectures.

In a HOF approach to safety management, in order to efficiently benchmark incidents and hence improve the safety of a facility, it is often pertinent to gather experiments from a variety of fields rather than from a single field. This ensures that we not only examine our personal experience but also the experience of others (cf. the notion of requisite variety in the next part as well).

\subsection{Variety of a system}

The focus here is on the "requisite variety" of the system (Ashby 1956). This stipulates that System X can only be fully controlled by system $\mathrm{Y}$ under the condition that the variety of System $\mathrm{Y}$ is equal or superior to the variety of system X (Ashby 1956, p. 124). "Variety" can be understood as the number of different behaviors and states of a system. The number of behaviors and states of a system is similar to the degrees of freedom of the system: the higher the degrees of freedom of a system, the greater the system's ability to control another system. As a very simple illustration, let us consider the ability to juggle a ball with one's feet. A person can perform this activity either by kicking the ball on its side or on its bottom as the ball drops. These different kinds of movement are possible thanks to the multiple degrees of freedom of the hip joint, which allow the leg to be flexed and rotated. In contrast, the ball cannot change direction on its own after being kicked.

In a HOF approach to safety management, requisite variety, and particularly the lack of variety has been identified as a significant cause in the difficulties encountered by workers during daily operations and as a cause of severe accidents.

\subsubsection{Requisite variety and the occurrence of severe accidents}

The controller may include the entire work situation (e.g., a cockpit and its crew, the man-machine interface and the specific procedures of interaction between the crew members), while the controlled systems can consist of merely the human counterparts (e.g., the crew members).

Many accidents have highlighted how difficult it is to achieve the required variety in the work situation, in particular, due to the complexity of human functioning (Amalberti 2013; Hardy and et Guarnieri 2012). As an illustration, the Tenerife disaster that occurred on March 27, 1977, resulted from a collision between two airplanes during takeoff causing the death of 583 people (collision of 2 Boeing 747) (Bernard 2014). This accident was mainly due to:
- An unusual situation at a saturated airport not designed for this type of traffic,

- A degraded perception of the actual runway situation (the presence of fog at the airport was not unusual); however, this perception was based solely on the communication between the control tower and the pilots of the planes on the runway, and

- Finally the lack of adequate communication between the crewmembers of the plane during takeoff.

Several recommendations were made after the accident, but above all, this tragedy resulted in the introduction of the "crew resource management" (CRM) procedures, which consist of a more formalized communication and coordination techniques between the crew members (Fornette and Jollans 2016). These procedures enforce increased variety in the cockpit. Indeed, one of Boeing 747 pilot's inadequate mental representation of the situation was due to his failure to take in information from his flight engineer. With CRM, the pilot-in-command is required to follow a procedure of cross control prior to takeoff. During CRM training, teams are taught to be mindful of potential biases (during the Tenerife disaster, the young co-pilot gave excessive deference to the senior pilot in command). Thus, the required variety of information has been growing in cockpits since the introduction of CRM procedures.

\subsubsection{Requisite variety and the difficulty of controlling a system}

The concept of requisite variety can be applied to the problem of socio-technical systems whose designers increased the level of automation without consideration for the overall performance (Bainbridge 1983). This usually results in a decrease in the users' degrees of freedom and consequently in the machines' degrees of freedom, due to an inadequate interactions between machines and users. This is a phenomenon called "the out-of-the-loop syndrome" (Endsley et al. 2003), results in a loss of user knowledge and know-how and induces a vicious circle that ultimately leads to machine underuse. To avoid this syndrome, an operator such as a driver or a pilot must have enough degrees of freedom in order to use the technical system correctly. He must know the current state of the technical system and anticipate its functions (Hardy and Guarnieri 2012).

Therefore, in design of a system, one must consider the trade-off between minimizing the operator's degrees of freedom in favor of maximizing the automation's degrees of freedom (Amalberti 2013). In certain cases, it may be more profitable to allocate functions to human operators rather than to automate them, even if the latter appears to be more efficient (Amalberti and Mosneron-Dupin 1997). For example, when important parameters need to be verified prior to 
the commencement of a complex operation, it is often more efficient to allocate these checks to the workers rather than to automatons. Particularly, as a "green light" or "ok" emitted by the control board indicates that the value of one parameter is correct, but fails to provide information of the value of this parameter such as its proximity to the limit. Therefore, the allocation of these checks to workers rather than automatons facilitates a progressively build-up of the mental representation of the situation, an important step necessary to perform the subsequent complex operation correctly.

\subsection{Coherence between system factors}

Coherence refers to the adaptation between system factors. It expresses the concept of interaction and allows the creation of an explicative model that offers recommendations that may act on the factors that influence the system outputs. This kind of explicative model provides a representation of the coherence or adaptation between the system factors (Vautier et al. 2018). Being coherent is equivalent to being well suited to one another. ${ }^{2}$ Note that, it is often necessary to build a descriptive model first to describe the functioning of the system. This descriptive model can represent the relationships of matter (for example a document that is sent by postal mail), of energy (an email is sent) or of information.

In a HOF approach to safety management, two basic kinds of models exist: a descriptive and an explicative model. A descriptive model may concern a man-machine system during which, for example, a human pushes a button and a computer emits lights. This type of model describes the interactions between a man-machine interface and a worker. For example, it can describe a physical interaction, the press of a button that in turn activates an alarm emitting an array of lights and sounds from the man-machine interface. Explicative models focus on the coherence or adaptation between the factors of a system. These relationships express the ability of the factors of a work situation to fit or adapt amongst each other (Tosello et al. 2003). The factors of a work situation may include the local work organization (e.g., objectives, tasks, and roles) as well as the system elements (e.g., workers, machines, tools, premises). Such models help take into consideration the role of system factors, such acoustical flows of noise and lighting conditions, and their adaptability in local work situations.

Finally, coherence also applies to the relationship between a work situation and its organizational factors. For example, in the design of a work situation such a control room, the

\footnotetext{
${ }^{2}$ Other models may include other types of interactions besides that of coherence. For example, certain actors may be linked together by convergent versus divergent relationships. For example, this expresses the fact that they agree (converge) or disagree (diverge) on the way to solve a problem.
}

allotted human resources and time must be adapted to the type of man-machine interface, an interface that should be customized to be most adequate and efficient for the process being monitored.

\subsection{Causal interaction in a system}

The relationships between the different factors of a system may also express the impact, or causal influence, that one factor has on another. More precisely, they express the manner in which one factor can modify or be modified by another factor.

In a HOF approach to safety management, this refers to the influences of not only the local workplace factors on worker performance, but also the impact of organizational factors on these local workplace factors (cf. the Swiss Cheese Model 3, Reason et al. 2006). It is another way to represent the notion of interaction between the factors an interaction between performance and local workplace factors and between local workplace factors and organizational factors.

This model provides a framework to explain all sorts of accidents, from the occupational/day-to-day life accidents to the industrial kind.

Let us look at an occupational accident that could also occur outside of the workplace, for example a postman, a worker in a large plant or oil tanker that falls off his bike. Attributing blame to the quality of the bicycle materials (a local workplace factor), points our gaze toward the process that influences the quality of these materials such as the maintenance of this process (an organizational factor). Hence, the idea of a "drop-down menu" effect expresses how a set of factors are connected by causal relationships. This becomes further apparent when there is a "click" or a visual focus on a human failure.

If the coherence between the local work place factors is considered, it can be represented in a triangular relationships between the quality of the bicycle materials, the work environment and the competences of the biker. Indeed, a worker with a high level of competence and biking ability would typically take a path that is compatible with the quality of the bicycle materials, particularly as he recognizes the potential consequences surrounding this compatibility and hence understands how to best use this kind of bicycle. 


\section{Main benefits of the seven system characteristics for a HOF approach to safety management}

After presenting our findings of the seven system characteristics relevant for a human and organizational factors approach to safety management, we highlight the following two main benefits of integrating these characteristics:

- An improved understanding of how industrial sociotechnical systems function,

- A compendium or a set of guidelines to implement actions in an industrial socio-technical system.

Finally, at the end of this chapter, we present a summary table that discusses the previous two benefits according to each of the seven characteristics.

\subsection{Improving the understanding of the functioning of an industrial socio-technical system}

\subsubsection{Making the different kinds of factors and interactions in a socio-technical system explicit}

One of the benefits of the concept of constitution of a system (cf. § 2.1) is that it assists managers and designers to identify numerous factors of the system, thus ensuring that important factors are not overlooked.

Focusing on the coherence in a system (cf. § 2.6) or on the causal interactions (cf. § 2.7) enables HOF specialists to build explicative models of a system. This makes it possible to clearly distinguish between different kinds of interactions: a physical interaction (for descriptive models), an adaptation or causal interaction (for explicative models).

Several accidents including the Paddington rail collision that occurred in 1999 in the United Kingdom (Cullen 2000) and the loss of the Columbia space shuttle in 2003 (CAIB 2003) highlighted the increasing organizational complexity of systems.

In a HOF approach, and particularly during an organizational analysis, it is essential to determine whether the organizational network potentially has direct or indirect involvement in the causation of the accident (cf. § 2.7). The first step (cf. § 2.2) is to distinguish the hierarchical (vertical) relationships from the a-hierarchical (horizontal) relationships between for instance competitors. This allows us to determine: Do the relationships only contain a top-down approach? Or are the relationships complemented with bottom-up approach, during which the feedback from the field and the weak signals are heeded?
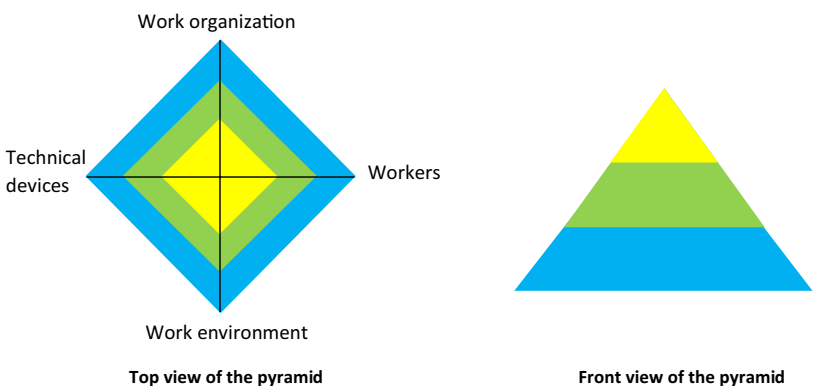

Top view of the pyramid

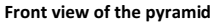

: Human activity : Local factors of a work situation

Organizational factors

Fig. 1 Model of the HOF pyramid

The second step examines the formality of the communication channels: Are interactions only of a formal nature? This implies an exchange of information only when required through coordination mechanisms. Or are the interactions complemented with informal nature? That is, are the interactions more open and fluid thus facilitating the sharing of negative news in order to cooperate and resolve any potential problem before an accident occurs?

In practice, it is the system characteristics such as coherence and causal interactions that define the graphical representation of a descriptive and an explicative model, and give meaning to its boxes and arrows. A single factor is often represented in its individual box connected to another box or factor by an arrow. This arrow may represent the different kinds of interactions: physical, adaptation, or causal interactions.

Finally, during a profound and extensive HOF analysis, it would be perhaps relevant to create a graphical representation of this analysis that uses the two concepts: coherence and causal interaction. We propose a pyramid-shaped HOF representation of these concepts, which consists of three levels similar to the three proposed by Reason et al. (2006) in the SCM3. Human and organizational factors are stalked on top of each other in the following manner: organizational factors at the base (in blue); local factors of a work situation in the middle (in green); and human activity at the top (in yellow). These three levels are linked by causal interactions. Moreover, coherence factors are considered within the middle and the base level. That is, the coherence between local factors at the medium level and in a separate level, the coherence between organizational factors at the base level. At these levels, four generic factors are considered: work organization, workers, technical devices, and work environment. The size of these factors depends on the level of the pyramid.

Figure 1 shows two views of a HOF pyramid: a top view and a front view. 


\subsubsection{Understanding why human failures occur}

The notion of coherence between the factors of a system (cf. 2.6) when compared with causal interactions (cf. § 2.7) better explains human failures, mistakes, or incidents (delays) and hence better explains unwanted emergences (cf. $\S 2.4)$. This can be illustrated by the interactions between the work environment in which driver competence, the type of car and the starting time may explain whether a driver is able to reach his destination. Hence, this notion of "puzzle" effect expresses the concept of adaptation between the factors.

Another example of emergence of human failure or an unsafe act occurs when workers do not wear gloves or other safety equipment when they should be wearing them. A model that takes into account coherence between the factors can describe the interactions between the gloves and the other characteristics of the work situation. For example, a worker may choose not wear their gloves due to incompatibilities or maladjustments between the characteristics of the gloves and:

- the task (if accuracy is required and the gloves are not sufficiently thin and elastic, or if there is a speed requirement and the worker is afraid to miss the production objective);

- the workers' competence (if training sessions are necessary to correctly put on and remove gloves), or motivation to wear them (if it unclear why the gloves are necessary);

- the work environment (if the gloves are not adapted to a wet heat environment).

\subsubsection{Introducing a fractal view of industrial socio-technical systems}

Aristotle's definition of a system based on the four causes includes the design and construction of the system in its constitution. Thus, Aristotle implicitly proposed a fractal view of the systems. Indeed, the first three causes of a system (material, formal, and final) can be seen as factors in the work situation, whereby designers or makers use tools to achieve a goal to satisfy an order in the work environment. Considering this new system, the fourth cause or the moving cause can be seen as a way of training the previous designers or makers and of designing their tools (Vautier 2015). And so on, several times, but this remains something to investigate further.

Nevertheless, there appear to be practical limits to deeper root cause analysis. Indeed, in a HOF approach, the work situation is often used as a scoping factor to restrict the perimeter of the analysis. Historically speaking, work situation analysis was applied to activities where potential errors would be critical and could induce deadly accidents. Thus, often impacting the end of an organizational chain. Examples of this include operators in a nuclear plant control room, the driver of a train and the pilot of a plane. Unfortunately, it would take time before the routine examination of maintenance work, engineering design work, and managers, corporate leaders, or regulators decisions were examined. Even to this day, it still far from being complete (Dien et al. 2012; ESReDA 2009).

\subsection{Guiding actions on the system}

\subsubsection{Examining a large variety of possible actions}

A formal definition of a system, particularly one based on the constitution of a system (cf. § 2.1) grounded on Aristotle's causes, can serve as a support in guiding the actions taken in industrial socio-technical systems. A HOF approach to safety management might thus consider:

- The elements and how to improve specific properties of these elements (for example factors of a work situation like worker competence, task duration, as well as characteristics like the size of the safety department in the case of larger systems);

- The arrangement of the elements (for example an effective arrangement of control room workstations so to optimize the collective activity of workers, or the rearrangement of a departments so to maximize the flow of inputs into outputs and thus prevent delays in delivery (avoiding bottlenecks) which often induce dangerous acts by workers);

- The finality (for example tasks, safety policy, and safety management system performance criteria);

- The design, production and maintenance of tools, procedures, and skills. This can include alternate ways of managing a work group, such as participative methods.

In practice, acting on the factors of a work situation means adding or modifying them through the use of current or new organizational factors. Current organizational factors may be activated (for example a skill deficit can be alleviated either through company training or through a recruitment processes already in place in the company) or new organizational factors may be introduced or modified from existing factors. This can be illustrated by workers' performance, which depends on their tools, skills, task demands, and work environment. When focusing on a single factor, such as a worker's tool, we can observe that the quality of the tools is generally dependent on the purchasing process, the skills and training required to use the tool, and the task demands of the design process; and also dependent on other processes like the learning from past events process (even 
if it may not be already exist in the plant). Then, human performance can be improved by numerous ways. One way may be to introduce a new process, such as the creation of a new process that promotes learning from past events during which workers experienced difficulties of using the tools (should this process not already exist). Another way could be adding a modification to current process, while continuing to use non-modified original process.

\subsubsection{Providing coherence to act efficiently on the systems}

If one factor changes then the adequate combination of the adapted factors may become inadequate. For example, let us consider a work situation with a driver in a car whose objective is to travel from town A to town B by a certain time, whereby the original departure time was set based on an optimal climate situation (sunny skies). In the event of rain, the driver will need to adapt the departure time to meet the deadline (the driver departs at an earlier time). However in the event of snow, changes will take place not only with regard to the departure time (an earlier depart than in the case of rain), to aspects of the car (fitted snow tires), but also to the driver himself (assigning a driver with ice driving experience). This implies that in order to regain a new balance, it is the coherence between the factors (cf. § 2.6) that "drives" the change of these factors.

In the same way, let us once again consider a group of students in a training room, in which the competence level of each student is important. If we aim to maximize communication within the group, then a U-shaped row of tables will facilitate discussion between the participants (students and the trainer). To further promote communication and avoid conflicts between the trainer and the group, a difficult student may be positioned at the side of the $\mathrm{U}$, rather than in front of the teacher. Other shapes exist and corresponding to other goals. For example, during exams desks will be better organized in rows while increasing the distance between the students. Consequently, achieving a high level of human performance entails careful consideration of the coherence between the elements (trainer + students), the arrangement of the elements, and the finality we hope to reach.

Finally, if we take Aristotle's moving cause into account, coherence also covers the relationships between this cause and the other causes (from the local factors of a system). For example, the time needed to prepare a training room has to be adapted to the table configuration, which is itself based on the purpose.

\subsubsection{Supporting the design of industrial socio-technical systems}

3.2.3.1 Contributing to HOF standards Let us consider a HOF illustration, one in which unanticipated interactions between the elements of a working system function defectively, due to inadequate functional arrangement between them (cf. § 2.4). For example, the analysis of the 1979 Three Mile Island nuclear (TMI) accident (Llory 1999) shows the results of the mismatch between the control room's manmachine interface and the operators' ability to build an adequate mental representation of the process. The plant operators perceived the switching on of a particular light in the control board to indicate the automaton was operating to close a valve. However, this was not true. In fact, as the light only indicated the order to close the valve had been sent (by the automaton). With this sequence, an inadequate cognitive automatism arose in the operators' brain. The problem arose as the valve, was blocked in a half-open position, despite the fact that the order to close had been sent. Thus, in 1979, this cognitive automatism induced the operators to overlook a safety automaton since their mental representation of the state of the reactor was incorrect. This was one of the causes of the accident.

The TMI accident revealed weaknesses in the design process of the control board with particular mismatches between the elements of this man-machine system. The concept of emergence of human errors and functional arrangement (cf. § 2.4) may have emphasized to the designers the importance of using tools that provide information, thus allowing the workers to adequate match the different of this man-machine system. HOF standards are one such tool and must be used in addition to technical standards. Asides from the numerous standards that have been developed to design systems, HOF specialists have proposed and developed the Human-centered design approach. Human-centered design uses an approach to develop interactive systems that aims at producing user friendly systems focused on the user's needs and requirements, and by applying human factors/ergonomics, as well as usability knowledge and techniques (ISO 9241-210). Human-centered design aims at optimizing the distribution of functions between individuals and the technical devices of future industrial socio-technical system. This distribution contributes directly to the quality (in particular the required variety) of this incoming system. Thus, this implies that the concept of requisite variety (cf. § 2.5) contributed to the birth of HOF standards.

Placing the human at the "center of the design" averts the risk of considering future socio-technical system workers as an "adjustment variable," due to their great capacity for adaptability to face situations unforeseen during the design of the system.

In summary, HOF standards such as the International Organization for Standardization (ISO standards) or the International Labour Organization (ILO) aim at helping managers and designers building more efficient socio-technical systems. 
3.2.3.2 Multiplying the viewpoints in a group Applying the concept of requisite variety (cf. $\S 2.5$ ) to a group of actors contributes to a better understand of unwanted events and allows a more efficient evaluation of the safety demonstration of a company.

Indeed, the fact that the limits of a system (cf. § 2.3) depend on the different viewpoints of its actors implies that the limits of a system of causes also depend on those contributing to the analysis of the unwanted event. Thus, we can increase the range of causes through the recruiting of different actors for the analysis. In particular, the composition of the analysis team is of primary importance to produce richer in-depth analyses of system events with larger boundaries. This is why ESReDA (2009) recommends a multidisciplinary team in order to increase the number of viewpoints of the system (Garandel and Périnet 2013). Essentially, it is recommended to include different organizational departments in a work group.

At a regulatory level, it is interesting to note that, like many high-risk industries, the nuclear industry follows controller/controlled logic. In France, the Nuclear Safety Authority (ASN) regulates the French nuclear safety. To give a practical answer to "How safe is safe enough?", the ASN is supported by a technical support organization (TSO), named IRSN (Institute for Radiological Protection and Nuclear Safety), that investigates and assesses safety, independently from the operator and regulator. To further enlarge the set of viewpoints and increase its variety, the ASN also consults with non-governmental organizations (NGO) and the nuclear safety council. The latter is composed of several experienced active and retired experts from all stakeholders in the nuclear industry: the nuclear power plant operator EDF, the fuel manufacturer and waste recycling operator Orano (former AREVA group), the nuclear research operator CEA, the TSO IRSN, as well as professors from universities active in the domain and some NGO representatives.

In summary, according to the HOF views, it is necessary to use methods, tools, and team project with adequate varieties in order to better design, build, maintain, and operate industrial socio-technical systems, according to safety requirement, throughout the life cycle of these systems.

\subsection{A synthetic table of the benefits to use system characteristics}

The benefits of integrating systems thinking in a HOF approach to safety management, previously discussed, are summarized in Table 1:

\section{Conclusion}

Human and organizational factors (HOF) contribute to building smarter, more reliable and safer industrial sociotechnical systems as they provide ways to study human performance and the factors, which influence it. In particular, HOF investigations deal with the underlying causes of human performance as well as the different paths between the causes and the performance. In this way, HOF fits systemic approaches very well.

Moreover, the IAEA (2016) recently advocated for the development of systemic approaches in nuclear safety, which remains a challenge in a domain dominated by engineering thinking.

Thus, seven system characteristics (constitution, multiaxis representation, limit, emergence, variety, coherence, and causal interaction) were identified in this article and illustrated with examples from HOF to show the benefits of their use in this field. This article proposes two key directions to consolidate the introduction of systems thinking in the HOF field. The first direction is to improve the understanding how industrial socio-technical systems function. The second direction is to guide actions within these systems.

This article demonstrates that several system characteristics are currently used by HOF specialists in safety management, despite not being at the origin of a systemic framework. It may appear like Mr. Jourdain ${ }^{3}$ stated, we have been "doing prose without being aware of it"! However, we argue that a better application of the underlying systemic properties would not only increase the benefits but also complement other systemic concepts of the existing HOF approaches. For example, some systemic tools such as system dynamics or the dialogical pairs (Vautier et al. 2016) should be perhaps utilized even more than current practices.

Finally, questions from HOF practices should be of interest to systems thinking experts and could suggest directions for future research.

Theoretically, the first three Aristotle causes might also apply to other systems other than a work situation such as a plant, or an entire company. The fourth cause may apply to factors, which condition the quality of the other systems. Nevertheless, how many times do this recurrent process appear in the different systems? Particularly, as it is known that a fractal property exists only several times in the life of system (for example the fractal structure of the ramifications is less extended in the small intestine than in the lungs).

\footnotetext{
${ }^{3}$ In France, Mr Jourdain is a well-known classic literature character. This expression means that we may carry out many tasks without knowing the principles underlying them.
} 


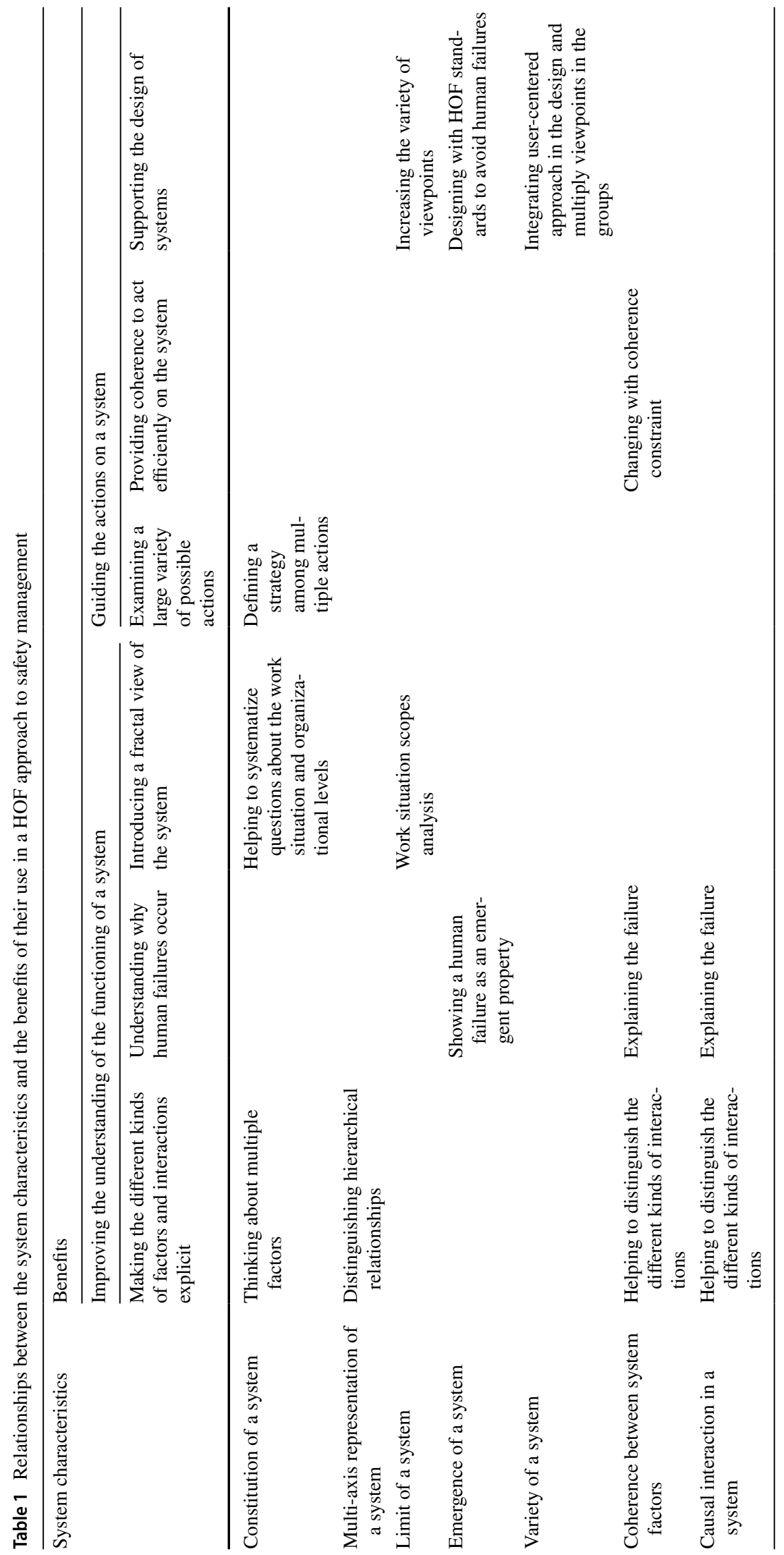


Finally, a recurring theme in the HOF field surrounds the question "At what point do we stop the analysis?". This is a question that can be tackled through the concept of the limit. In fact, if we focus on the system of causes during an unwanted event analysis, the question surrounding the concept of limit is twofold and highlights the depth and breadth of safety management analyses: does the range of causes have an extensive breadth? And are the chains of causes sufficiently deep? The notion of "sufficiently" is related to the minimum amount of factors necessary to point out and act on in order to efficiently prevent the recurrence of similar unwanted events.

Acknowledgements The authors would like to thank Gaël Laurans, $\mathrm{Ph} . \mathrm{D}$., for his contribution to the language editing of this paper and the two blind authors for their challenging comments.

\section{References}

Amalberti R (2013). Navigating safety, necessary compromises and trade-offs - theory and practice, Springer, The Netherlands

Amalberti R, et Mosneron-Dupin F (1997) Facteurs humains et fiabilité: quelles démarches pratiques? OCTARES Editions

Aristotle (1930). Physics, Book II, Chaps. 3 and 7 (trans: Hardie RP, Gaye RK). Oxford Press, Oxford

Aristotle (2008) Metaphysics (The original is in French: Métaphysique). In: Book $\Delta$, Chap. 2, Translation of Marie-Paule Duminil et Annick Jaulin. Editions Garnier Flammarion, Paris

Ashby WR (1956). An introduction to cybernetics, Chapman \& Hall, London

Bainbridge L (1983). Ironies of automation, Automatica, 19(6):775-779

Bernard B (2014). Comprendre les facteurs humains et organisationnels - Sûreté nucléaire et organisations à risques, EDP Sciences

Bignell V, Fortune J (1984). Understanding system failures, Manchester University Press, Manchester

CAIB (2003). Report Volume 1, national aeronautics and space administration, Washington DC, available at http://caib.nasa.gov

Cullen WD [Lord] (2000) The Ladbroke grove rail inquiry, Part 1 and Part 2 reports. HSE Books, Her Majesty's Stationery Office, Norwich

De Rosnay J (1975) Le macroscope. Seuil, Paris

Dechy N, Rousseau J-M, Llory M (2011). Are organizational audits of safety that different from organizational investigation of accidents? ESREL 2011 Conference, Troyes, France, pp. 18-22

Dechy N, Dien Y, Funnemark E, Roed-Larsen S, Stoop J, Valvisto T, Vetere Arellano A-L, on behalf of ESReDA Accident Investigation Working Group (2012). Results and lessons learned from the ESReDA's accident investigation working group, Saf Sci, 50(6):1380-1391

Dekker S (2006), The field guide to understanding 'human error'. Ashgate Publishing Limited, Farnham

Dekker S (2011), Drift into failure: from hunting broken components to understanding complex systems, Ashgate Publishing Limited, Farnham

Descartes R (1637). Discours de la méthode

Dien Y (2006) Les facteurs organisationnels des accidents industriels, dans L. Magne. In: et Vasseur D (eds) Risques industriels - Complexité, incertitude et décision: une approche interdisciplinaire. Éditions TEC \& DOC, Lavoisier, pp 133-174
Dien Y, Llory M, Montmayeul R (2004) Organisational accidents investigation: methodology and lessons learned. J Hazard Mater 111(1-3):147-153

Dien Y, Dechy N, Guillaume E (2012) Accident investigation: from searching direct causes to finding in-depth causes. Problem of analysis or/and of analyst? Saf Sci 50(6):1398-1407

Endsley M, Bolte B, Jones D (2003). Designing for situational awareness: An approach to user-centered design. Taylor and Francis, Routledge

ESReDA (2009) Eds., ESReDA working group on accident investigation, Guidelines for safety investigation of accidents, available http://www.esreda.org

Fornette M-P, Jollans J-Y (2016). Former les équipes à la sécurité et à la performance avec le crew resource management. Octares Editions, Toulouse

Garandel S, Périnet R (2013) A daisy to multiply the points of view in analyses of events, Third European Conference for High Reliability Organizations, 5, 6 november 2013, Aix-En-Provence

Grant E, Salmon P, Stevens N, Goode N, Read G (2018) Back to the future: what to accident causation models tell us about accident prediction? J Saf Sci 104:99-109

Haeckel E (1899) Riddle of the Universe at the Close of the Nineteenth Century

Hardy K, et Guarnieri F (2012) Modéliser les accidents et les catastrophes industrielles: la méthode STAMP. Editions Lavoisier, Paris

Hollifield BR, Habibi E (2010) The alarm management handbook, 2 edn. PAS, Houston, TX

Hollnagel E, (2012), FRAM: the functionnal resonance analysis method: modelling complex sociotechnical systems. Ashgate Publishing Limited, Farnham

Hollnagel E, Woods D, Leveson N, (2006), Resilience engineering: concepts and precepts. Ashgate publishing limited, Farnham

IAEA (International Atomic Energy Agency) (2013). Human and organizational factors in nuclear safety in the light of the accident at the Fukushima Daiichi nuclear power plant, International Experts Meeting, 21-24 May 2013, Vienna, Austria

IAEA (International Atomic Energy Agency) (2016). Leadership and Management for Safety, GSR Part 2

ISO 9241-210, Ergonomics of human-system interaction-Part 210: human-centred design for interactive systems, January 2011

Koffka K (1935) Principles of Gestalt psychology

Le Moigne J-L (1977) La théorie du système général, théorie de la modélisation (2nd edn in1994)

Leveson N (2004) A new accident model for engineering safer systems. J Saf Sci 42:237-270

Lewes G-H (1875) Problem of life and mind

Llory M (1999) L'accident de la centrale nucléaire de Three Mile Island, Éditions L'Harmattan, Paris

Llory M, et Montmayeul R (2010). L'accident et l'organisation, Editions Préventique, Paris

Manna G (2007). Human and organizational factors in nuclear installations: analysis of available models and identification of R\&D issues, JRC Scientific and Technical Reports

Mill J-S (1862). A system of logic

Perrow C (1984). Normal accidents, living with high risk-technologies, Princeton University Press, Princeton

Rasmussen J (1997) Risk management in a dynamic society: a modelling problem. Saf Sci 27(2-3):183-213

Rasmussen J, Svedung I (2000) Proactive risk management in a dynamic society. Swedish Rescue Services Agency, Karlstad

Reason J (1990). Human error, Cambridge University Press, New York

Reason J (1997) Managing the risks of organisational accidents. Ashgate, Aldershot

Reason J, Hollnagel E, Paries J (2006) Revisiting the « swiss cheese » model of accidents. EUROCONTROL 
Rousseau J-M, et Largier A (2008). Conduire un diagnostic organisationnel par la recherche de facteurs pathogènes, Techniques de l'Ingénieur AG 1576

Tosello M, et Vautier J-F (2001). Présentation et illustration d'une démonstration de sûreté «facteurs humains », XXXVIth congress of SELF, Montréal, Canada, 3-5

Tosello M, Vautier J-F, Sevestre B (2003). A new study of human factors in the nuclear safety field, XVth Congress of the International Ergonomics Association (IEA), August 24-29, 2003, Seoul, Korea, 5, SAFETY V

Turner B (1978). Man-made disasters, Wykeham Publications, London Underwood P, Waterson P (2013) Systemic accident analysis: Examining the gap between research and practice. J Accid Anal Prev 55:154-164

Vaughan D (1996) The challenger launch decision. Risky technology, culture, and deviance at NASA. The Chicago University Press, Chicago

Vautier J-F (2007) “Art et Systémique" La gouvernance dans les systèmes. Polimetrica, January

Vautier J-F (2008) A systemic approach to question complexity: the systemic scores, 7th Congress of the European Union for Systemics EUS-UES, Lisbon
Vautier J-F (2015) Making a causal contextualization with the four causes of Aristotle. Adv Syst Sci Appl 15(2), 176-187

Vautier J-F, Tosello M, Hernandez G, Dutillieu S, Quiblier S, Sylvestre C, Lévêque F, Barnabé I, Baussart N, Paulus V, Lipart C, Barrière V, Dupont M (2016). A synchro-diachro approach to question the development of a human and organizational factors (HOF) network, International Conference on Human and Organizational Aspects of Assuring Nuclear Safety-Exploring 30 years of safety culture, IAEA, Vienna, Austria, 22-26

Vautier J-F, Dechy N, De Coye Brunélis T, Hernandez G, Launay R (2018). Systemic characteristics of a human and organizational factors (HOF) approach of safety management, in Cybernetics and Systems by Routledge

Von Bertalanffy L (1968) General system theory: foundations, development. George Braziller, Canada

Wilpert B, Fahlbruch B (1998). Safety related interventions in interorganisational fields, In: Hale A, Baram M (eds), Safety management - the challenge of change, Elsevier Science Ltd, Pergamon, pp 235-248 